\title{
RESEARCH ON AGRICULTURAL E-COMMERCE PUBLIC TRADE PLATFORM SYSTEM
}

\author{
Qifeng Yang ${ }^{1, *}$, Bin Feng ${ }^{1}$, Ping Song ${ }^{1}$ \\ ${ }^{1}$ Economics College of Wuhan University of Technology Wuhan, Hubei, 430070 P. R. China \\ * Corresponding author, Address: Economics College of Wuhan University of Technology \\ Wuhan, 122, Luoshi Road, Hongshan Disct, Wuhan, 430070, P. R. China, Tel: +86-27- \\ 87383196, Fax: +86-27-87651809, Email: yangqifengwhut@163.com
}

Abstract: As we know, the decentralized management of agricultural production is inconsistent with the big market and circulation in our country. Facing this situation, we suggest strong enterprise construct third party agricultural public trade platform under the guide of the government in a way of market-based operation. The drive to build such platform from government, enterprises, peasant and agricultural organization was analyzed. The framework, function module and logic structure of the platform system were designed. In order to realize the sustainable development of the platform, we suggest the government should strengthen the function of the role in the platform construction and operation. Besides, we should improve the functional innovation, technological innovation and management innovation of the platform continuously to give full play to its economic and social benefit, and led the three sides that the government, peasant and enterprise to win together.

Keywords: Agriculture, e-commerce, trade platform, system structure

\section{INTRODUCTION}

China is a large agricultural country, and the agricultural resource in china is abundant, and its distribution is extensive. The agricultural production value accounts for a great proportion of the GDP of China. With the development of the market economy, the problems in the agricultural production come out conspicuously day-by-day. The circulation of

Yang, Q., Feng, B. and Song, P., 2008, in IFIP International Federation for Information Processing, Volume 259; Computer and Computing Technologies in Agriculture, Vol. 2; Daoliang Li; (Boston: Springer), pp. 933-942. 
agriculture hinders the development of the countryside and becomes one of the most important factors, which influence the income increasing of peasant and the stability of the countryside. The information technology, network technology and the e-commerce commercial mode, inject life and vigor into agriculture of our country. By integrating each resource of the traditional agriculture, utilizing the advanced, convenient technology to construct agricultural information platform, the online agricultural commerce can be realized. These are useful to improve the management state and strengthen the competitiveness of the agricultural production, and will exert a farreaching influence on the reform and development of the rural social economy in our country.

Nowadays, the agricultural production in our country mainly is decentralized management mode in which the manpower, financial resources and technologies of each managing enterprises are weak. (Xia et al., 2003) However, it is unrealistic to develop their own e-commerce platform independently, because it will add their operation cost and cause resource wasting. In this situation, the way of constructing a third party agricultural e-commerce platform is effective. Firstly, most peasants do not have high literacy, and it's difficult for them to grasp the use of PC terminal station and Internet's function. Secondly, the economic condition is limited, and it's difficult for them to buy and use the modern network device. Thirdly, the construction and maintenance of the information system will be very difficult. In this case, the construction of the third party e-commerce public trade platform is an effective way. Under the support of social forces and government, the third party agricultural e-commerce platform regards district as centre, and provides e-commerce services for agricultural production of this area. (Yi, 2006) Meanwhile, it radiates to peripheral area, provinces and cities, and can offer e-commerce support to peasant in this area effectively. On the basis of agricultural information website, the platform can supply with agricultural production trade service, including agricultural demand, logistics and price information.

\section{DRIVE OF THE AGRICULTURAL E-COMMERCE PUBLIC TRADE PLATFORM CONSTRUCTION}

The industrial informational development in some districts lags behind relatively because of low developed economy. So the large agricultural products are produced blindly. This led to social resource to waste seriously. The agricultural e-commerce platform uses the information technology to provide the information promulgation and collection such as supply, demand and price information. Beside, it utilizes the network and agricultural 
production base and logistics system to make the trade and payment convenient, safe and fast. The advantages of the platform are obvious. It not only cuts down the trade cost by reducing the intermediate link, makes the lagging agricultural economy realize great-leap-forward development, but also led the traditional agriculture break through the space-time limitation; effectively solve the problem that the agricultural production and market information are unsymmetrical. (Yi et al., 2007) Besides, it can improve the organization degree of agricultural production, the agricultural value chain of our country and competitiveness; elude the risk of product price fluctuation. In addition, the need of the government, enterprise, peasant and agricultural organization are the drive of the construction of agricultural e-commerce public trade platform.

\subsection{The government needs the social benefit of agricultural e-commerce platform}

This platform has typical external benefit, and can help the amalgamation of the decentralized management of agricultural production with the big market and circulation. It also can improve the agricultural market circulation system so as to use the informationization to promote the development of the traditional agriculture. Meanwhile, the construction of the agricultural e-commerce public trade platform helps the government to carry on the macro adjustments and controls of production means. By the mean of constructing information platform between the regulation and control department of the government and the department who provides the production mean, the manager can know the distribution situation of the production mean. Moreover, it makes the operation, regulation and control more transparent, and realizes the facilitation of information technology to national economy.

\subsection{The agricultural e-commerce public trade platform improves the peasants' income and living standard}

As to peasants and agricultural organization, the agricultural public trade platform is undoubtedly a tool to obtain market information and increase probability of selling the products. By the platform, peasants can get information about price, weather, agricultural machinery and market, etc. So it's possible for them to know which kind of crops is suitable for them to plant. This reduces the blindness of agricultural plant. In addition, they can buy seed, chemical fertilizer and agricultural machinery through Internet, and sell their products at the same time. Regarding agricultural public trade platform as carriers, we can concentrate decentralized peasants, and set up an online agricultural countryside commune. (Yan et al., 2005) Under the 
organization of powerful agricultural intermediary made by the Internet, the peasant produce according to the order, and do the global agricultural futures business online for 24 hours. This provides new developing opportunity for peasants and agricultural organization, and improve their income and living standard greatly too.

\subsection{The agricultural e-commerce public trade platform increases the profits of the enterprises}

Because of the support of policy and peasant, enterprises including the user enterprises and platform operating main body enterprise can benefit from the platform. The user enterprises including agricultural producing enterprise, marketing enterprise and processing enterprise can share information together, and cut down the stock cost, improve their ability to adapt to the risk and the perceptibility of opportunity by the platform. It is useful for them to optimize the resource distribution, promote marketing and reduce cost so as to win together. For example, the production of the agricultural producing enterprises can be supplied to agricultural processing enterprises as raw materials, or to be sold wholesale to the agricultural marketing enterprises. At the same time, they can know the demand of the processing enterprises and marketing enterprises to the production in time. So it's possible for them to control production rationally, adjust the stock, reduce cost and increase benefit. After the processing enterprises reprocess the products from producing enterprises, they can sell the new product to the marketing enterprises. Thus the processing enterprises can know the demand of the marketing enterprises and make rational producing plan. Likewise, the marketing enterprises can obtain production from upriver supplier timely, know the market-supplying situation, and make rational price strategy. Similarly, because of the support of the government, with the increasing of the platform users, the platform operating main body enterprise, namely the enterprise that constructs and operates the platform, can regain the cost and make profits gradually while perfecting the function and maintaining the operation of the platform.

\section{SYSTEM DESIGN OF THE AGRICULTURAL E-COMMERCE PUBLIC TRADE PLATFORM}

\subsection{System framework design}

The agricultural e-commerce platform public trade platform adopts the multi-layer system structure. System integrates information and trade service 
of $\mathrm{B} 2 \mathrm{~B}$ and $\mathrm{B} 2 \mathrm{C}$ mode, and its core is the database server. It provides information data service for the authorized users by application server and authentication system. The whole framework of the system is shown below (fig. 1).

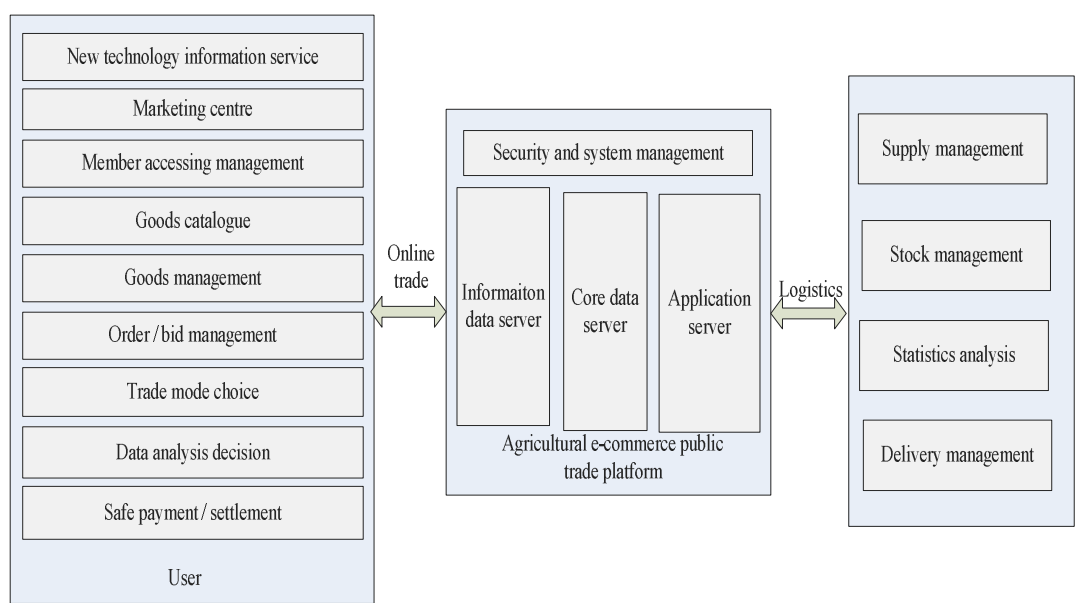

Fig. 1. System framework of the agricultural e-commerce public trade platform

\subsection{System function design}

(1) Online trade. The online trade is the core function of the system. We need to realize trade negotiation, negotiation management, and contract management. The system combines many ways to realize convenient and fast business negotiation such as E-mail, audio and video communication.

(2) Goods management. System provides function for managing the goods circulation and intelligent goods information inquiry. Based on database of agricultural machinery and byproducts processing equip, system carry on the data mining, analysis, realize the inquiry and statistics function, and predict the market trend.

(3) Payment system. On the basis of safe and reliable certification system, the platform provides many functions to create convenient commerce environment such as account management, payment settlement, client report form management and so on.

(4) Logistics. The logistics system of the platform connects the logistics centre of the user enterprises, the third party logistics company, and the post net logistics.

(5) Member management. According to users of different layers, platform provides service of different layers, such as credit evaluation.

(6) Information and data service. Platform provide functions for practical and new technology intercourse, enterprise and production information 
issuance, technology and news dynamic issuance, policy and regulation inquiry, goods information issuance and so on.

\section{DESIGN OF EACH FUNCTION SUBSYSTEM}

\subsection{Agricultural market information collection and issuance system}

This subsystem includes three parts: (1) Domestic and international market information collection, analysis, prediction and issuance. (2) Domestic and international production means information collection, analysis and issuance, such as seeds, chemical fertilizer and pesticide. Thus the agricultural production means producer can put out their production fast and the peasants can get the production means the quality of which can be guaranteed in time. Besides, the platform develops the order agriculture, which is becoming an important way to develop the agricultural industrial management in our country. The order agriculture can meet the need of enterprises and peasants, create a new way to earn foreign exchange, increase peasants' income, and expedite the pace of agricultural informational development.

\subsection{Market trade digital management system}

The platform utilizes the information technology to realize integrative management of person, money and goods of this public trade market. Based on this, the digital management system improves the work quality and efficiency of the market, and its standardized management. The main function of this subsystem include management of store, stall, charge, industrial and commercial license, tax registration, certificates, warehouse, personnel, attendance, price issuance and so on.

\subsection{Agricultural trade intelligent communication system}

The platform provides safe and accurate information issuance about supply and demand information of both sides of the trade. Besides, we will study the intelligent automatic matching of the information issuance and its issuance standards. Thus, the problem that supply and demand information of both sides is blocked can be solved. 


\subsection{Visual e-commerce trade system}

The platform will develop visual e-commerce trade system that suits products of some kinds of agriculture such as planting and feeding. The user can issue their product information to the trade system by PC, phone or text message. The agricultural production trade information intelligent communication engine then match the information. If there is a match, the engine will inform the both supplier and the buyer. The users can also browse or search for the production information themselves.

\subsection{Agricultural e-auction system}

This part is to study the feasible auction way, and to keep the e-auction information is dependable, undeniable and identifiable. Based on this, the platform develops the agricultural e-auction system that stress on demand and actual effect.

\subsection{System logical structure design}

The logical structure of the system is shown in fig. 2, which is made up of local program server, data baking up server and work terminal.



Fig. 2. Logical structure of the agricultural e-commerce public trade platform

\subsection{Network system}

The basis of the agricultural e-commerce platform is a perfect, safe and reliable network which can be divided into three parts: (1) External network connection groupware, including WAN connection equipment such as router, dial-up accessing server, issuance server such as DNS, mail repeater; (2) Internal network connection groupware such as internal server group. 
(3) Network security device and software, including fire wall system, network security scanning software, network real-time monitoring software, Web monitoring and resume system, etc.

\subsection{Software system}

The basic system structure of the software system of the platform is shown in fig. 3.

Agricultural e-commerce public trade platform is a complicated system, whose software development and data amount are very large. Besides, it will use a lot of complicated technology. So we had better provide a middleware to support it. This middleware should support large-capacity system, complicated trade, various front-end, multi-database, complicated communication way and business logic, and be able to integrate other application system. The platform uses some technologies such as the Web and Java, and all kinds of application server to realize the business management of the platform. Besides, there is an interface to the other information system of the enterprises.

\subsection{Security system}

The security system of the agricultural e-commerce public trade platform is use for preventing secret information form revealing and trespassing. However, the Internet itself is designed based on open idea. It's difficult to be definitely safe on the Internet. The security of the data can be divided into four aspects that security of data; integrity of data, certification, and data is undeniable. In order to keep data safe from these four aspects, the security system of the platform is constructed from four aspects below too. (1) Physics security. Keep the computer network device from destroying of man-made operation or accident such as earthquake, floods, and fire. (2) Network security. It includes the security of system, namely host computer and server, network operation security, LAN security. (3) Information security. It includes the security of information transmission, storing and the audit of information content. The main technologies are encrypt, digital signing, e-certificate, e-envelope and double signing etc. (4) Trade security. It includes the identity validation, trade affirmation and information transmission security. The platform will provide reliable security services such as differentiation service; access controlling service, confidentiality service and so on. 


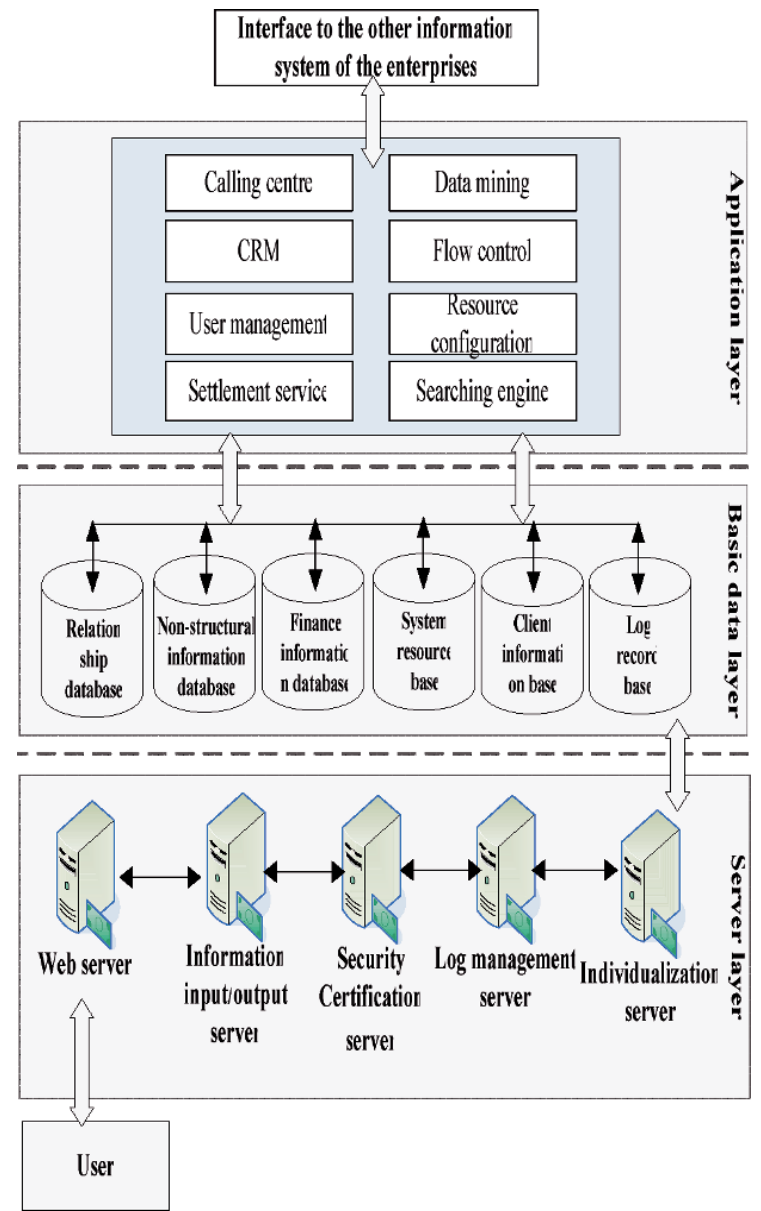

Fig. 3. Software system structure of the agricultural e-commerce public trade platform

\section{CONCLUSIONS AND EXPECTATIONS}

The mode that certain strong enterprise constructs the agricultural e-commerce public trade platform under the lead and support of the government is an ideal mode to develop agricultural e-commerce. On one aspect, this platform has a typical social benefit, and will improve the development level of the whole agricultural trade so as to improve income and living standard of the peasants. On the other hand, it helps the amalgamation of the decentralized management of agricultural production with the big market and circulation, and perfect the agricultural market circulation system. Moreover, the platform help agricultural product of our country to consolidate the domestic market, and go out to the world and capture the world market. 
In order to realize the sustainable development of agricultural e-commerce public trade platform, there are several suggestions for the construction and operation of the platform. First, the government should strengthen the function of the role in the platform construction and operation. The agricultural e-commerce public trade platform is a complicated system engineer that refers to many factors such as hardware, software technologies, finance system and legal environment. The government needs to be active to organize and coordinate all kinds of resource to service the platform better. Meanwhile, agriculture is always a weak quality industry with the characteristics such as high cost, long production cycle, big risk, low benefit, and it's difficult to absorb investment. So, during the development of platform, the government should make a lot investment on the construction of basic information facilities, development of frontier technologies and the construction, maintenance and update of the basic database. Secondly, we should carry on the function innovation actively, fully consider user' education level in the design and upgrading of the platform and reduce the complexity of the platform using. Thirdly, we should develop the technological innovation of the platform, and create more prefect function for the platform-using network and computer technologies. Finally, improve the management innovation of platform based on the basis mentioned above, and try to establish management system, which suits the actual situation in this area so as to pave the way for the operation of the platform.

\section{ACKNOWLEDGEMENT}

This research was supported by the Doctor Fund of Wuhan University of Technology under Grant 471-38650316.

\section{REFERENCES}

Xia Wen Hui, Logistics operation mode of agricultural production on e-commerce platform, Rural Economy, No. 7, 2003

Yan Chuliang, Tian Zhaofeng, E-commerce platform construction of agricultural machinery and byproduct, Transaction of The Chinese Society of Agricultural machinery, No. 1, 2005

Yi Famin, EC Platform and Electronic Integration of Agricultural production Supply Chain, Finance and Trade Research, No. 6, 2006

Yi Faming, Xia Jiong, Research on agricultural Supply Chain integration based on e-commerce platform, On Economic Problems, No. 1, 2007-7-14 